losophers such as Leon Kass, Jürgen Habermas and Francis Fukuyama is at times abrasive. But, whether or not one agrees with Harris's position, he dissects their opposing claims with impressive effectiveness. He makes a persuasive case that today's biotechnologies - including neuroengineering, stem-cell research and cloning to improve bodies and brains - are on the continuum of an age-long pursuit by humans to improve themselves and therefore, he argues, are permissible and morally essential.

I question the author's contention that choices such as non-medical sex selection can be as straightforward as picking a white shirt over a Hawaiian one, or that "inevitability is the only reason dying of old age is acceptable". But I do agree that everyone - scientists, ethicists and the public — has a role in the research enterprise, not least because of benefit sharing. That is not to say that we should all be drafted into research, and certainly no end would justify exploitation of children and people with diminished abilities, but service to society by its members is an honourable goal.

Aubrey de Grey and Michael Rae's Ending Aging is a more 'new-wave' treatment of enhancement, longevity and immortality. Through chapters with catchy titles, such as 'Putting Zombies to Rest', and gripping language - "I shall look forward to shaking your hand in a future where engineered senescence is a reality" - the authors call for research that will deliver a life expectancy to match that of Methuselah, the oldest of the people whose age (969 years) is mentioned in The Bible.

Ending Aging guides the reader through a maze of advances in molecular and cellular biology that could lead to anti-ageing therapies, which the authors term SENS (for 'strategies for negligible senescence'). The targets are a range of cancer-causing nuclear and mitochondrial mutations, intracellular and extracellular debris, and molecular crosslinks that contribute to pathological decay over a lifetime.

The authors rather unnecessarily brand ageing as repugnant and a curse, and use their book to preach on fund-raising opportunities. By contrast, de Grey's 2005 publication on 'Life extension, human rights, and the rational refinement of repugnance' in the Journal of Medical Ethics (co-edited by Harris) is still an edgy but more dignified treatise.

The freedom to pursue ways to enhance human mental and physical capacities and to eliminate negative aspects of the human condition, such as suffering and death, is a fundamental tenet of the trans-humanist movement. Although seemingly worthy, there are problems ahead for the futurists, including for Harris, de Grey and Rae. At what age should life-prolonging measures begin - in utero, when development of the nervous system peaks in the mid-20s, or much later? What would become of natural rhythms in wisdom and folk psychology, and how will the roles of elders be redefined? Would we immortalize some and punish others by withholding life-prolonging intervention - reconfiguring the term 'life sentence' and introducing new systems of justice for the parallel mortal and immortal populations?

Will people be able to step off the immortality train when they are ready? Will suicide increase if we move life expectancy into the hundreds? We cannot remove longevity like a pair of spectacles. And abuse is reported by $1-10 \%$ of old people surveyed, mostly directed against women. If society shows increasingly scant regard for centenarians, how will it treat people of 1,000 years old?

Let's not throw away today for tomorrow. Ending Aging is likely to appeal to those already converted to the authors' views, and perhaps will find some traction among those who are more curious than interested in deeper scientific engagement. I end unconvinced by Harris's view, but my interest was piqued by the diverse ways in which physical and mental health, autonomy, culture, and respectful and caring community systems can be realized. After we have maximized human well-being and compressed morbidity to minimize suffering (see A. Kalache et al. Bull. World Health Organ. 80, 243-244; 2002), then let's think about life extension, step-by-step, one decade at a time.

Judy Illes is professor of neurology at the National Core of Neuroethics, University of British Columbia, Vancouver V6T 2B5, Canada.

\title{
Archimedes' secrets revealed
}

\section{The Archimedes Codex \\ by Reviel Netz \& William Noel \\ Weidenfeld \& Nicolson/Phoenix/ \\ Da Capo Press: 2007. 336/336/320 pp. \\ €18.99(hbk)/£8.99/\$27.50 (pbk)}

\section{Brian Clegg}

In April 2004, biologist Lewis Wolpert won a debate at the Royal Institution in London entitled 'Who was the first scientist?' He championed Archimedes. Although I reckon Roger Bacon comes closer to deserving that label, the result reflects the respect still felt for Archimedes' work. Yet our knowledge of his output has never been complete. The Archimedes Codex describes the recent uncovering of text from the Archimedes canon not read since the parchment forming the codex was reused to make a prayer book in 1229 .

Only three of Archimedes' books in the original Greek are known, two of which have been lost since first being transcribed. The third, this codex, had never been fully deciphered. Access to the earliest known version (from the tenth century) was important because of a recent shift in interpretation of Greek texts. The Greeks approached mathematics visually. The diagrams and the exact wording used are crucial in understanding the thinking of a Greek mathematician - yet when the lost Archimedes manuscripts were transcribed, no thought was given to capturing the visual nature of the information.

In The Archimedes Codex, Reviel Netz and William Noel contribute alternate chapters, with Noel describing the history of the codex and the work undertaken to decipher it, and Netz exploring Archimedes' mathematics. This discontinuous style is initially unnerving - both authors write in the first person, and it isn't clear that the 'I' of chapter 1 is not the same person as the 'I' in chapter 2. But it soon settles into an engaging account.

Noel, director of the deciphering project, explains the intricacies of dealing with a manu-

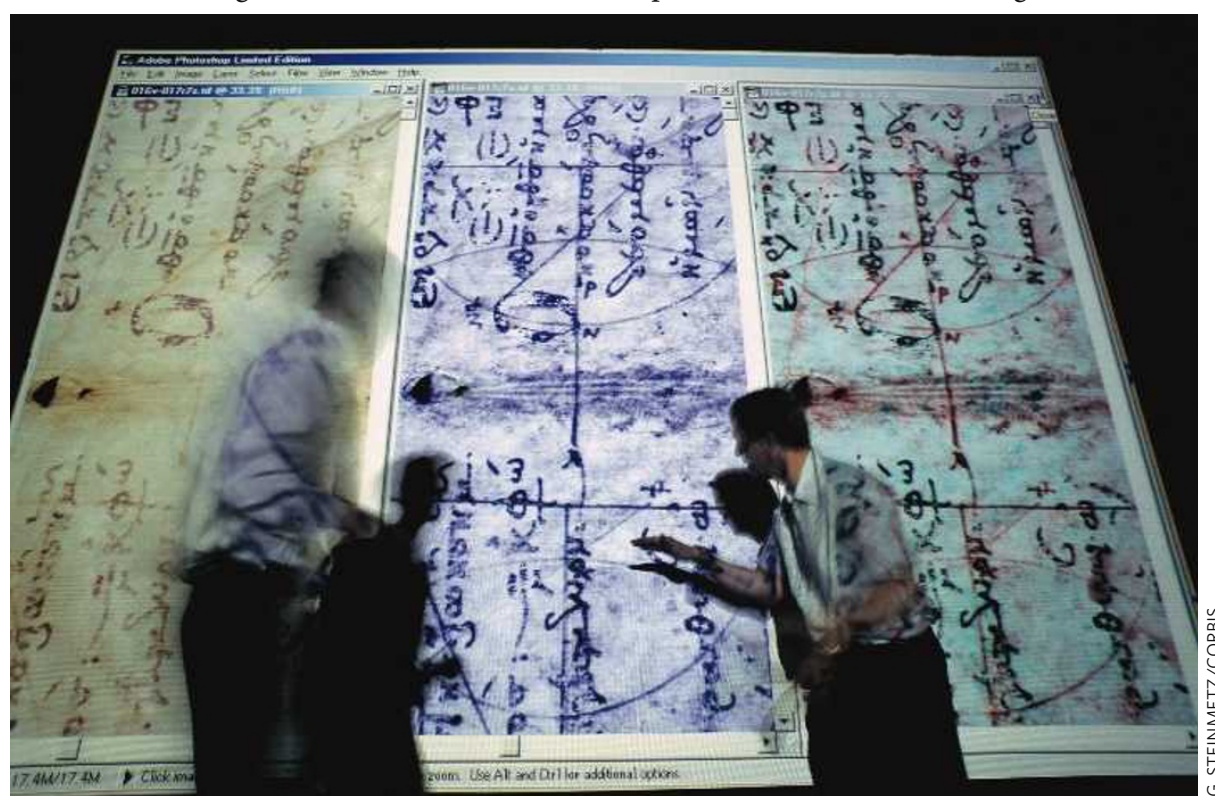

Analysing the Archimedes palimpsest with different wavelengths of light. 


\section{EXHIBITION \\ The liquid of life}

Josie Glausiusz

Atlanta, Georgia, will run out of drinking water within the next four months if it doesn't rain soon. The city is experiencing its driest year since 1931. Only a dramatic cut in water use can save the situation, officials announced in October. The average resident, like the average North American, uses between 227 and 340 litres of water per day.

Most of us would quickly use less water if we had to carry that much for miles every day on our heads in the type of brass jug toted by women in Jalalabad, Afghanistan. One such flower-etched vessel is on display at the American Museum of Natural History's new exhibition, Water: $\mathrm{H}_{2} \mathrm{O}=$ Life, and visitors are invited to lift it. Full, the jug weighs about 11 kilograms. I could barely raise it above my knees, let alone hoist it onto my head. Trudging home with hefty pitchers like this is a way of life for many: in some parts of subSaharan Africa, women spend between 15 and 17 hours a week collecting water.

Water: $\mathrm{H}_{2} \mathrm{O}=$ Life clearly conveys how vital water is to our existence, how imperilled we are without it, and how big the divide is between the affluent West, where water flows freely from taps at a cost of about a quarter of a US cent per litre, and poorer regions of the world, where shanty-town dwellers pay a premium for trucked-in water. State-of-the-art interactive video displays, the museum's dearly loved dioramas (one of a lifesize polar bear on ice), maps and satellite images detail grim statistics. For example, 20 litres per day is the minimum amount of clean water required to meet basic human needs - drinking, cooking and hygiene. Some people in parched places have to survive on just 5 litres or less. One quarter of Mexico City's residents have no access to tap water; others have only 1 hour a week.

The exhibit's emphasis is on water conservation, often at the expense of the esoteric science of water or the politics of its

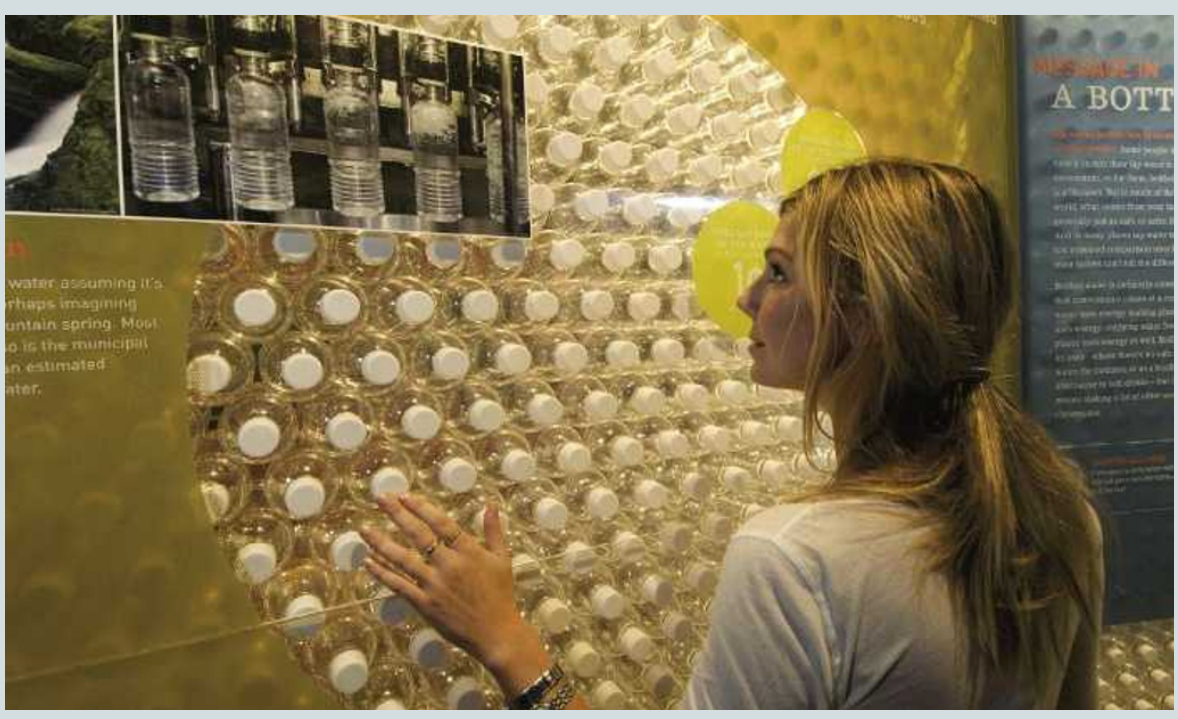

Bottle perspective: 3 litres of source water are used to make 1 litre of bottled water.

scarcity in many conflict zones. Information is largely pitched at the curious layperson or schoolchild - the show was instigated when a 2006 survey by the National Oceanic and Atmospheric Administration revealed alarming public ignorance. The beautifully designed displays excel at showing visitors how to save water and energy. A mound of plastic bottles explains that it takes 3 litres of water to produce a 1-litre bottle of the stuff; and that $40 \%$ of them in the United States are filled with filtered tap water - at 1,000 times the price.

The exhibit also artfully demonstrates the innovative methods that people are using to extract, conserve and purify water. More than 700 PlayPump water systems have been installed in rural South Africa and other sub-Saharan countries. Children spinning on these colourful merry-go-rounds 16 times per minute generate enough energy to pump about 1,400 litres of water per hour from boreholes 40 metres deep. (I enjoyed hand-whirling a miniature PlayPump to fill a toy jerrycan from a tiny tap.) Perth in Australia gets $20 \%$ of its water supply from the Indian Ocean, desalinated with wind power. Windhoek in Namibia reclaims up to $30 \%$ of its water from sewage.

Some water-purification methods on display are delightfully low-tech. Bangladeshi women have cut cholera incidence in half using sari fabric, folded eight times, to filter bacteria from water. This, more than a century-and-a-half since the link was first made between cholera and polluted water. That connection prompted UK authorities to build separate water mains and sewerage tunnels emptying downstream into the Thames river, a system that is still in use. The Thames and Lee rivers now supply drinking water to 8.3 million residents in the London area every day. Alas, modernity does not always equal progress. Many times a year the antiquated system spews hundreds of millions of litres of untreated sewage directly back into the rivers. With some stretches of pipe more than 100 years old, the city itself accounts for $25 \%$ of water leakage in Britain. Whether in sodden London or arid Atlanta, saving water is a hard habit to learn, it seems.

Josie Glausiusz is a New York-based science journalist and editor, and author of Buzz: The Intimate Bond Between Humans and Insects.

Water: $\mathrm{H}_{2} \mathrm{O}=$ Life runs at the American Museum of Natural History in New York until 26 May 2008. It will then tour the United States, Australia and Canada until 2011. script of this age and of uncovering the hidden text beneath the overwriting. His contribution has a personal tone ideal for the palimpsest story but rather too lightweight for scientific technicalities such as the mechanism of the multispectral imaging used to bring out the obscured text. Netz, a classicist at Stanford University, makes less allowance for his audience. His valuable examples may warrant several rereadings for non-mathematicians.

The most exciting of the discoveries in the newly deciphered text was Archimedes' use of infinity. The Greeks were wary of infinity, a concept they endowed with implications of chaos and disorder. When infinity was con- sidered in Greek mathematics, it was treated as potential infinity, rather than the real thing. A potentially infinite pile of logs will never run out - there are always more - but it contains a finite, if indefinite, number.

Before the codex was deciphered, it was thought that, apart from some playful consideration of true infinity by Galileo Galilei, the concept was hardly touched on until the nineteenth century. Netz painstakingly retrieves text from the codex proposing that two infinite sets have the same size because the elements in them can be put in a one-to-one correspondence. Such sets are now said to have the same 'cardinality', the modern concept that estab- lishes that two sets are equivalent in magnitude. Yet here was Archimedes using this argument more than 2,000 years before Georg Cantor added it into the mathematical armoury.

Netz also shows how Archimedes used a remarkable physical extension of geometry to calculate the area under a parabola, and undertakes some work based on a game called the stomachion (bellyache). However, it is Archimedes' use of the infinite that has the biggest impact on our understanding of the history of mathematics and that best demonstrates the value of Netz and Noel's work. Brian Clegg is the author of $A$ Brief History of Infinity and editor of www.popularscience.co.uk. 